Beverly K. Philip MD, David A. Scott MD, Dubravka Freiberger MD, Richard R. Gibbs MD, Catherine Hunt MD, Ellen Murray RN

\title{
Butorphanol compared with fentanyl in general anaesthesia for ambulatory laparoscopy
}

Butorphanol was compared with fentanyl as the narcotic component of general anaesthesia for ambulatory laparoscopic surgery. This double-blind, randomized study enrolled 60 healthy women who received equianalgesic doses of fentanyl I $\mu \mathrm{g} \cdot \mathrm{kg}^{-1}(F, n=30)$ or butorphanol $20 \mu \mathrm{g} \cdot \mathrm{kg}^{-1}(B, n=30)$ prior to induction of anaesthesia. Tracheal anaesthesia was maintained with nitrous oxideloxygen, isoflurane, and succinylcholine by infusion. Intraoperatively, patients who received $B$ demonstrated lower pulse rate before and after intubation $(P<$ $0.05, P<0.01)$ and lower diastolic blood pressure after intubation $(P<0.01)$. Anesthesiologists judged the maintenance phase as satisfactory more often with $B(P<0.05)$. Postoperatively, there were no differences in analgesic need. No major side-effects occurred in either group. Among minor side-effects, patients who received $B$ reported postoperative sedation more often, $77 \%$ vs $37 \%(P<0.01)$, which occurred during the first 45 min of recovery $(P<0.05)$. Discharge times were not different. On the first postoperative day, more subjects who received $B$ were satisfied with their anaesthesin experience $(P<0.05)$. Butorphanol $20 \mu \mathrm{g} \cdot \mathrm{kg}^{-1}$ is an acceptable alternative analgesic in general anaesthesia for ambulatory laparoscopy.

Nous avons comparé les effets du butorphanol à ceux du fentanyl lors de laparoscopies faites en externe. Soixante patientes ont participé à cette étude double-insu. Avant l'induction de l'anes. thésie, on leur injectait à titre d'équivalem analgésique, soit $1 \mu \mathrm{g} \cdot \mathrm{kg}^{-1}$ de fentanyl (groupe $F, n=30$ ), soit $20 \mu \mathrm{g} \cdot \mathrm{kg}^{-1}$ de butorphanol (groupe $B, n=30$ ). Après l'inlubation de la trachée, elles respiraient de l'oxygène, du protoxyde d'azote et

\section{Key words}

ANAESTHESIA: outpatient;

ANALGESICS: butorphanol, fentanyl.

From the Department of Anesthesia, Brigham and Women's Hospital, Harvard Medical School, Boston, MA, USA.

Address correspondence to: Dr. Beverly K. Philip, 75 Francis Street, Boston, MA 02115, USA.

Supported in part by grants from Anaquest, Murray Hill, NJ and from Bristol Laboratories, Evansville, IN, USA.

Accepted for publication 10th October, 1990. de l' isoflurane associés à une perfusion de succiny/choline. Les patientes du groupe B avaient un pouls plus lent avant et après l'intubation $(P<0,05 ; P<0,01)$ de même qu'une tension artérielle diastolique plus basse après l' intubation $(P<0,01)$. Les anesthésistes ont jugé favorablement la phase de maintien de l'anesthésie plus souvent chez les patientes du groupe $B(P<$ $0,05)$. En période postopératoire, les besoins en analgésiques étaient les mêmes dans les deux groupes avec de la sédation qui, quoique plus fréquente dans le groupe $B$ ( 77 vs $37 \% ; P<$ $0,01)$ durait moins de $45 \mathrm{~min}(P<0,05)$. Nous n'avons observé aucun effet secondaire important et la durée du séjour en salle de réveil érait semblable chez les groupes $F$ et $B$. Le lendemain de l'intervention, les patientes du groupe $B$ cotaient leur anesthésie avec plus de satisfaction $(P<0,05)$. Lars d'ume anesthésie générale pour fin de laparoscopie en externe. l'usage de butorphanol est tout à fait acceptable.

Narcotic analgesics are widely used as adjuncts to outpatient general anaesthesia. They act to smooth the intraoperative course and decrease the requirements for other anaesthetic agents, as well as to minimize postoperative pain. It is, however, imperative that any agent used in ambulatory anaesthesia have a short duration of action and minimal side-effects, so that patients can be discharged home safely.

Butorphanol is a morphinan chemically related to levorphanol, and has mixed agonist-antagonist properties. ${ }^{1-3}$ It is a kappa receptor agonist as well as a mu-receptor antagonist, resulting in analgesic and sedative properties without profound respiratory depression or euphoria. These properties make it a potentially useful drug for ambulatory surgical patients. The purpose of this study was to compare low doses of butorphanol with fentanyl, a popular short-duration opioid, as a component of general tracheal anaesthesia for ambulatory laparoscopic surgery. Both the intraoperative anaesthesia course and postoperative recovery characteristics were evaluated.

\section{Methods}

Sixty women scheduled for elective laparoscopy were enrolled in this study. Patients were ASA physical status I or II taking no psychotherapeutic medications and with no 
TABLE I Demographic data and durations of surgery and anaesthesia (units \pm SD)

\begin{tabular}{lcrl}
\hline & Fentanyl & Butorphanol & Significance \\
\hline Age (yr) & $28.1 \pm 11.4$ & $29.8 \pm 3.5$ & NS \\
Height $(\mathrm{cm})$ & $164.6 \pm 8.9$ & $162.3 \pm 7.4$ & NS \\
Weight (kg) & $63.2 \pm 10.3$ & $56.4 \pm 9.0$ & $P<0.01$ \\
Duration (min) & & & \\
- surgery & $12.2 \pm 5.3$ & $13.3 \pm 6.1$ & NS \\
- anaesthesia & $41.8 \pm 11.2$ & $44.3 \pm 9.7$ & NS \\
\hline
\end{tabular}

history of narcotic abuse. Institutional Human Subjects Committee approval was granted and written informed consent was obtained. Patients were randomly assigned to receive either fentanyl $(F)$ or butorphanol $(B), 30$ in each group.

The patients received no premedication. In the preoperative holding area, vital signs were measured and baseline Trieger dot tests ${ }^{4}$ and visual analogue scales $(\mathrm{VAS})^{5}$ for sedation, anxiety and pain were obtained. All assessments were made by a single observer. Two minutes before induction of anaesthesia, patients received an equianalgesic dose of either $1 \mu \mathrm{g} \cdot \mathrm{kg}^{-1}$ fentanyl or $20 \mu \mathrm{g} \cdot \mathrm{kg}^{-1}$ butorphanol iv, based on their body weight and given in a double-blind fashion. Induction of anaesthesia was with thiopentone $4 \mathrm{mg} \cdot \mathrm{kg}^{-1}$ followed by tracheal intubation facilitated with succinylcholine. Anaesthesia was continued with $60 \%$ nitrous oxide in oxygen, $0.4 \%$ isoflurane, and succinylcholine infusion. Vital signs were recorded after thiopentone (one to two minutes), after intubation (one and three minutes) and every $15 \mathrm{~min}$ during the procedure and until stable in the recovery room. An assessment of the induction, intubation and maintenance phases of anaesthesia was obtained from the anaesthetist as: satisfactory (needing no additional thiopentone or isoflurane) or unsatisfactory (requiring additional agent). The times of induction, surgical incision and closure, and time of orientation (from cessation of nitrous oxide) were all noted.

During recovery, patients' activity, respiration, alertness and colour were evaluated at 15 min intervals during the first $90 \mathrm{~min}$, and hourly thereafter. Trieger dot tests and visual analogue scales for sedation, anxiety and pain were performed at 15-min intervals from arrival in the recovery room for the first $90 \mathrm{~min}$, then half-hourly until $180 \mathrm{~min}$. Analgesic requirement and time to discharge were also recorded. Presence of adverse effects was determined by observation and by specific questioning during patients' recovery. Our standard Day Surgery Unit criteria were fulfilled prior to discharge.

Post-discharge follow-up was made by a telephone call on the following day. Patients were questioned about the occurrence of specific adverse effects. They were also
TABLE II Anesthetists' assessment of the maintenance phase of anaesthesia

\begin{tabular}{llcl}
\hline & Fentanyl & Butorphanol & Significance \\
\hline Satisfactory & 20 & 25 & $P<0.05$ \\
Unsatisfactory & 10 & 5 & \\
\hline
\end{tabular}

asked to give a general assessment of their anaesthetic experience as positive (good or pleasant), negative (not good or unpleasant) or neutral (acceptable).

Statistical evaluation was done with two-tailed unpaired $t$ tests for comparisons between groups and repeated measures ANOVA for multiple comparisons. Chi-square analysis with continuity correction was used for comparing proportions, and Fisher's exact test for small numbers. $P<0.05$ was considered significant.

\section{Results}

The two groups were not significantly different in duration of surgery or anaesthesia, baseline tests or demographic variables, except for weight (Table I). The anesthetists' assessments of the anaesthetic induction and tracheal intubation were not different between the groups, but the anaesthetic maintenance period was judged to be more satisfactory in B patients (Table II, $P<0.05$ ).

$V$ ital signs were comparable between groups except for the occurrence of a lower pulse rate in the butorphanol group, both before $(79 \pm 14[\mathrm{~B}]$ vs $89 \pm 15[\mathrm{~F}], P<0.05)$ and immediately after intubation ( $89 \pm 20[\mathrm{~B}]$ vs $103 \pm 20$ beats $\cdot \min ^{-1}[\mathrm{~F}], P<0.01$ ) (mean $\pm \mathrm{SD}$ ). Diastolic blood pressure in the butorphanol group also was lower immediately after intubation $(88 \pm 18[\mathrm{~B}]$ vs $101 \pm$ $17 \mathrm{mmHg}$ [F], $P<0.01$ ).

Postoperatively there were no differences in vital signs, need for intravenous or oral analgesics, or recovery as assessed by activity, respiration, alertness or colour. There were also no significant differences in recovery as assessed by Trieger dot tests and anxiety or pain VAS for $150 \mathrm{~min}$ after arrival in the recovery room. However, the sedation VAS demonstrated more sedation in B patients than $\mathrm{F}$ for the first $45 \mathrm{~min}$ in recovery, as well as longer time for return to baseline levels of sedation, at $60 \mathrm{~min}$ vs $30 \mathrm{~min}$ (Figure, $P<0.05$ ). There were no significant differences between the groups in the times to orientation or discharge (Table III).

TABLE III Times to patient orientation and to discharge (minutes $\pm S D)$

\begin{tabular}{lrr}
\hline & Fentanyl & Butorphanol \\
\hline Time to orientation & $15.0 \pm 15.2$ & $17.0 \pm 14.7$ \\
Time to discharge & $133.5 \pm 54.1$ & $149.3 \pm 56.1$ \\
\hline
\end{tabular}




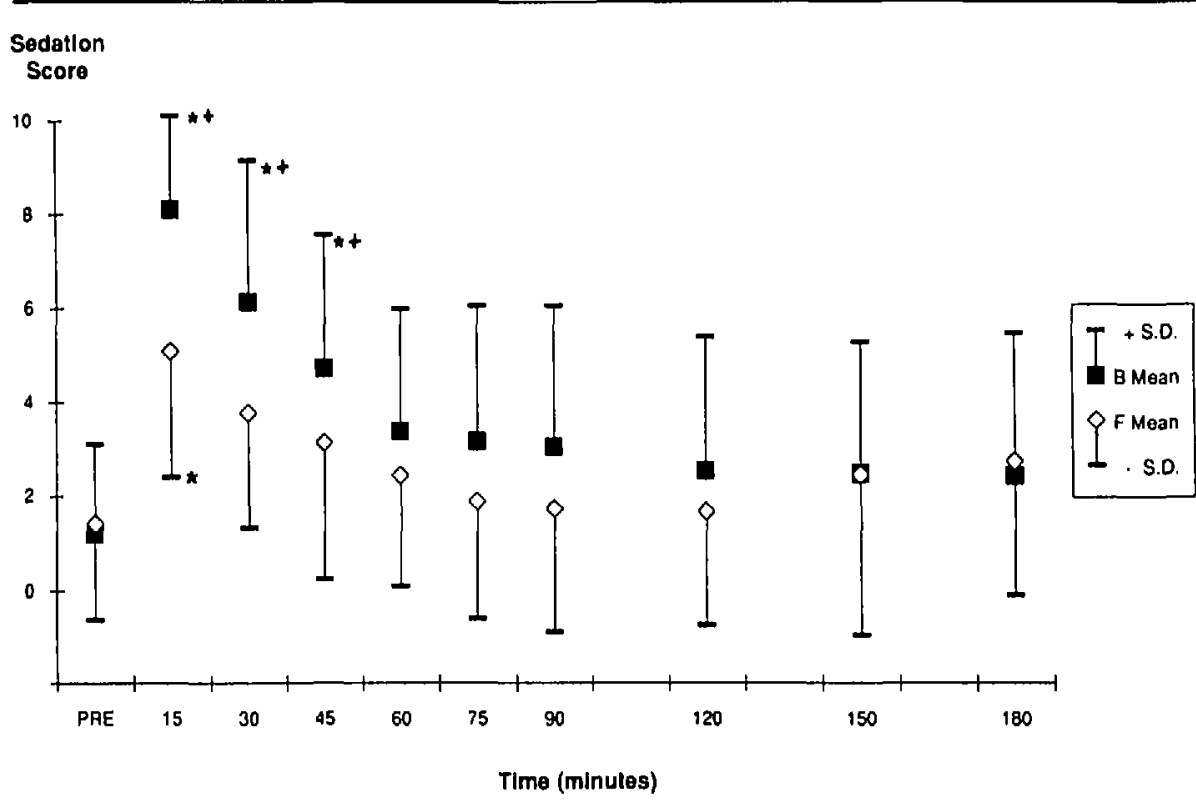

FIGURE Sedation VAS scores comparing butorphanol $(B, \square)$ and fentanyl $[F, O)$ preoperatively and during recovery. ${ }^{*} P<0.05$ versus preoperative baseline. $\dagger P<0.05$ versus $\mathrm{F}$ group.

There were no major complications such as respiratory depression or toxic reactions. Table IV summarizes the minor side-effects as reported by the patients. Sedation was the only significantly different experience, and was greater in the butorphanol group. Both groups experienced postoperative pain, $90 \%$ in $B$ and $93 \%$ in $F$. The requirements for additional analgesics in the postoperative period were also not different, as measured by the number of patients in each group who received intravenous or oral analgesics or by the number of doses administered. No patient required admission to hospital.

The follow-up telephone call, $24 \mathrm{hr}$ later, asked patients for a general assessment of their anaesthetic experience. Among those patients who expressed a definite opinion (other than a neutral response), significantly more patients who received $\mathrm{B}$ gave a positive assessment of their experience $(P<0.05$, Table $V)$.

\section{Discussion}

The characteristics which distinguish butorphanol from fentanyl are related to their opioid receptor spectra. Butorphanol is a kappa-receptor partial agonist as well as a weak mu-receptor antagonist, whereas fentanyl is predominantly a mu-receptor agonist. ${ }^{1,3,6}$ Butorphanol is therefore associated with more sedation than fentanyl, a kappa-agonist effect, and this was seen in our study. The patients who received $B$ experienced more sedation for the first $\mathbf{4 5} \mathrm{min}$ of recovery, and took longer to return to baseline levels of sedation than the patients who received F. However, this increased sedation did not affect the time
TABLE IV The incidence of minor side effects

\begin{tabular}{lccl}
\hline & Fentanyl & Butorphanol & Significarice \\
\hline Dizziness & 11 & 17 & NS \\
Excitement & 4 & 3 & NS \\
Headache & 5 & 4 & NS \\
Lightheadedness & 15 & 14 & NS \\
Nausea & 13 & 13 & NS \\
Vomiting & 9 & 10 & NS \\
Pain & 28 & 27 & NS \\
Sedation & 11 & 23 & $P<0.01$ \\
\hline
\end{tabular}

TABLE V Patients' general assessment of their anaesthelic experience on the nexı day, among those patients who expressed a definite opinion

\begin{tabular}{llll}
\hline & Fentanyl & Butorphanol & Significance \\
\hline Positive & 0 & 6 & $P<0.05$ \\
Negative & 6 & 3 & \\
\hline
\end{tabular}

to discharge, and may have contributed to the increased number of positive patient assessments on the next day. Butorphanol is also described as having sigma agonist activity, ${ }^{1,3}$ which can result in dysphoria and unpleasant dreaming experiences. ${ }^{2,3,7}$ However, we found no significant difference in the incidence of such side-effects between the butorphanol and fentanyl groups.

The ability to produce analgesia is associated with both kappa and mu opioid receptors. ${ }^{1,3}$ With butorphanol, the 
analgesic effect may be limited due to its partial kappa agonist activity. However, for ambulatory laparoscopic procedures, the intraoperative analgesic need is not profound and the dose of butorphanol used in this study appeared to be adequate, as indicated by the satisfactory assessment of anaesthesia maintenance phase. Postoperative pain was not eliminated by the dose of either opioid given in this study and the need for postoperative analgesics was the same for both opioid groups. The receptor profile of butorphanol also suggests that it should produce less respiratory depression than fentanyl:; ${ }^{1,3}$ this effect was not evaluated.

Other studies have compared recovery and discharge for ambulatory surgical patients with butorphanol and fentanyl. ${ }^{6,8.9}$ Higher doses of butorphanol ( 40 to $60 \mu \mathrm{g}$. $\mathrm{kg}^{-1}$ ) resulted in prolonged sedative effects and delayed discharge. Increased doses of fentanyl as the opioid component have also been shown to prolong recovery. ${ }^{8.9}$ We chose to limit the doses of opioids, and add instead isoflurane to complete the balanced general anaesthetic. This is consistent with routine clinical practice and enabled us to use doses of both fentanyl and butorphanol which were less likely to produce side-effects, including delayed discharge. In a study comparing butorphanol doses of $20 \mu \mathrm{g} \cdot \mathrm{kg}^{-1}$ with $40 \mu \mathrm{g} \cdot \mathrm{kg}^{-1}$ for ambulatory laparoscopic surgery, administration of the higher dose resulted in increased time to discharge readiness. ${ }^{9}$

Higher doses of butorphanol have also been associated with higher incidences of nausea and vomiting compared with fentanyl. ${ }^{8,9}$ In this study, the incidence of nausea and vomiting was the same in both opioid groups. Also, our overall rates of $43 \%$ (nausea) and $30 \%$ (vomiting) are similar or lower than reported in other studies of ambulatory surgery patients. ${ }^{6-8}$ This suggests that the lower dose we used avoids increased emetic symptoms that can be seen with higher-dose butorphanol, and the incidence is instead comparable with that seen with the use of fentanyl.

Pandit and colleagues ${ }^{8}$ measured perioperative vital signs during laparoscopy using higher doses of butorphanol and fentanyl, $40 \mu \mathrm{g} \cdot \mathrm{kg}^{-1}$ and $2 \mu \mathrm{g} \cdot \mathrm{kg}^{-1}$ respectively. They found that the patients who received butorphanol experienced smaller increases in heart rate and systolic blood pressure two minutes after intubation. In this study, patients who received a lower $20 \mu \mathrm{g} \cdot \mathrm{kg}^{-1}$ dose of butorphanol had lower pulse rate before and after intubation and lower diastolic blood pressure after intubation. These results are consistent with the earlier report. However, haemodynamic changes observed in both studies were from healthy patient populations undergoing ambulatory surgery. Whether these changes would occur or be beneficial in sicker patients undergoing other types of surgery cannot be determined from these data.
We conclude that butorphanol is an acceptable alternative opioid to fentanyl for use as a component of balanced general anaesthesia for ambulatory laparoscopic surgery, at the doses studied. Butorphanol $20 \mu \mathrm{g} \cdot \mathrm{kg}^{-1}$ may also exhibit some advantages in patient satisfaction.

\section{References}

I Rosow CE. Butorphanol in perspective. Acute Care 1988; 12 (suppl 1): 2-7.

2 Mitchell RWD. Smith $G$. The control of acute postoperative pain. Br J Anaesth 1989; 63: 2,147-58.

3 Jaffe $J H$, Martin WR. Opioid analgesics and antagonists. In: Gilman AG, Goodman LS, Rall TW, Murad F (Eds.). The Pharmacological Basis of Therapeutics, 7th ed., New York: MacMillan Publishing Co., 1985, 491-531.

4 Newman MG, Trieger N, Miller JC. Measuring recovery from anesthesia - a simple test. Anesth Analg 1969; 48: 136-40.

5 Marwell $C$. Sensitivity and accuracy of the visual analog scale. Br J Clin Pharmacol 1978; 6: 15-24.

6 Fine J, Finestone SC. A comparative study of the side effects of butorphanol, nalbuphine and fentanyl. Anesthesiology Review 1981; 8(9): 13-7.

7 Garfield JM, Garfield FB, Philip BK, Earls F, Roaf E. A comparison of the psychological effects of fentanyl and nalbuphine in ambulatory gynecologic patients. Anesth Analg 1987; 66: 1303-7.

8 Pandit SK, Kothary SP, Pandit UA, Mathai MK. Comparison of fentanyl and butorphanol for outpatient anaesthesia. Can J Anaesth 1987; 34: 2, 130-3.

9 Wetchler BV, Alexander CD, Shariff MSY, Gaudzels $G M$. A comparison of recovery in outpatients receiving fentanyl versus those receiving butorphanol. Journal of Clinical Anesthesia 1989; 1: 339-43. 